\title{
Pre-print in clinical medicine?
}

\section{José Luis Sandoval-Gutiérrez}

Secretaría de Salud, Instituto Nacional de Enfermedades Respiratorias "Ismael Cosío Villegas", Department of Pulmonology, Ciudad de México, Mexico

In the article "Preprints in biomedicine: alternative or complement to the traditional publication model?", published in Gaceta Médica de México 2018 number 2, year 154, vol. 65, pages 87-91, Aquino-Jarquín et al. addressed the convenience of using preprints in biomedicine.

Even when currently there are more biomedical journals, the number of works submitted for publication has increased and the criteria for accepting an article are also stricter, and thus the majority do not reach the publication phase and remain in editorial boards, posters, oral presentations oral or theses.

For a researcher, non-acceptance of an article is frustrating after the time invested on meeting the editorial and evaluation criteria of a high-impact factor journal.

Many procedures for obtaining the academic degree have been left pending owing of that dynamic, since to belong to academic excellence programs, a certain time is demanded for obtaining the degree, without having the possibility to postpone it beyond the agreed period.

The preprint publication alternative in biomedicine is a satisfactory solution that relieves bottlenecks that are experienced (and that will be greater in the future) to meet the completion requirements of a scientific work.

Preprint of works with results that might compromise a diagnosis or clinical treatment should go through an even more rigorous review process by the editorial board and peer reviewers.

In the biomedical field, the announcement of new findings (for example a new protein or a synthesis mechanism) does not affect medical care for many years until this discovery adds the participation of patients. But what happens when new knowledge that apparently could change the course of diagnosis, treatment or prognosis of a disease is made public?

If the information is correct, its value is incalculable, but it would put the well-being of patients at risk if it is incorrect and was not detected by the editorial board or peer reviewers of a journal.

From the clinical point of view, it is advisable waiting a "maturation time" that is required between the moment a finding is identified, published and implemented in patients. Let's follow the right steps to offer the best alternative to patients.

It only remains for me to congratulate the authors for the interest shown about this scientific problem.
Gac Med Mex. 2018;154:420-420

Contents available at PubMed www.gacetamedicademexico.com 